\title{
Manuscript Writing Workshop for Authors - 2018
}

\section{Rishi Pokhrel' and Barsha Bajracharya ${ }^{2}$}

'Department of Anatomy, College of Medicine, Nepalese Army Institute of Health Sciences, Kathmandu, Nepal

${ }^{2}$ Department of Dental Surgery, Nepalese Army Institute of Health Sciences, Shree Birendra Hospital, Chhauni, Kathmandu, Nepal

Dear Executive Editor,

Medical Journal of Shree Birendra Hospital organised a one-day manuscript writing workshop for authors on $6^{\text {th June }} 2018$ at Nepalese Army Institute of Health Sciences, Kathmandu, Nepal.

The workshop covered various aspects of medical research, writing and publishing including planning a research project, statistics, referencing, literature search, the art of writing, formatting of scientific manuscripts, submission, peer review and editorial process and ethical issues in medical research including plagiarism. The workshop included hands on practice on submission process of a manuscript in an actual journal.

The facilitators of the workshop were from Nepalese Army Institute of Health Sciences / Shree Birendra Hospital, KIST Medical College, Patan Academy of Health Sciences, Birat Medical College and Khyber Medical University, Pakistan. Participants were from 14 different institutions of Nepal and India and ranged from medical intern to head of departments, professors and consultants.

Brig Gen Dr Nagendra KC, Principal of College of Medicine, NAIHS inaugurated the workshop and the closing and certificate distribution was done by Maj Gen Dr Bachchu Ram KC (retd.), Executive Director of NAIHS. The workshop was activity based and two external evaluators evaluated the workshop. Pre and posttests were conducted and feedbacks were taken for each session followed by a summative feedback at the end of workshop.

The feedback from participants and evaluators was extremely positive with some suggestions for improvement like to increase the duration of workshop. Students $t$ test of pre and post-test showed a $p$ value of 0.0052 , a significant improvement in knowledge. The workshop was accredited by Nepal Medical Association with education credit of five hours.

Dr Rishi Pokhrel and Dr Barsha Bajracharya

Managing Editors, Medical Journal of Shree Birendra Hospital,

Kathmandu, Nepal.

Correspondence: Rishi Pokhrel, Department of Anatomy, College of Medicine, Nepalese Army Institute of Health Sciences, Kathmandu, Nepal. Email: rongon28us@yahoo.com

DOI: http://dx.doi.org/10.3126/mjsbh.v17i2.20472

Submitted on: 2018-6-22

Accepted on: 2018-06-29

This work is licensed under creative common license:

http://creativecommons.org/licenses/by-nc-nd/4.0/ C MJSBH 2018 